\title{
PROPOSTA DE IMPLEMENTAÇÃO DE AÇÕES PARA MELHORAR O CLIMA ORGANIZACIONAL A FIM DE APERFEIÇOAR A QUALIDADE DOS SERVIÇOS NA CLÍNICA: ESTUDO DE CASO NA CLÍNICA DE OLHOS HARLEY STREET
}

\section{ARTIGO ORIGINAL}

PIRES, Iverton Daniel Morais ${ }^{1}$, COELHO, Victória Rebecca Farias ${ }^{2}$, OLIVEIRA FILHO, Fábio Augusto de ${ }^{3}$, ALMEIDA, Victor da Silva ${ }^{4}$, ROBERTO, José Carlos Alves $^{5}$

PIRES, Iverton Daniel Morais. Et al. Proposta de implementação de ações para melhorar o clima organizacional a fim de aperfeiçoar a qualidade dos serviços na Clínica: Estudo de caso na Clínica de Olhos Harley Street. Revista Científica Multidisciplinar Núcleo do Conhecimento. Ano. 06, Ed. 11, Vol. 07, pp. 72-91. Novembro 2021. ISSN: 2448-0959, Link de acesso: https://www.nucleodoconhecimento.com.br/administracao/o-clima-organizacional, DOI: 10.32749/nucleodoconhecimento.com.br/administracao/o-clima-organizacional

\section{RESUMO}

O exposto artigo teve como objetivo realizar um estudo de caso na Clínica de Olhos Harley Street, atuando no ramo da saúde ocular na cidade de Manaus, a clínica é de médio porte e dispõe de dois pontos de atendimento aos clientes. O objetivo geral da proposta foi descrever como melhorar o desempenho dos serviços prestados pelos colaboradores na clínica por meio da introdução de estratégias para melhoria do clima organizacional. A partir dos resultados e das análises dos estudos

\footnotetext{
${ }^{1}$ Graduando do curso de Administração.

${ }^{2}$ Graduanda do curso de Administração.

${ }^{3}$ Graduando do curso de Administração.

${ }^{4}$ Coorientador. Mestre em Engenharia de Processos. Pós-Graduando em Neuro psicopedagogia Institucional. Especialista em Gestão Estratégica de RH. Graduado em Administração e Pedagogia.

${ }^{5}$ Orientador. Mestre em Engenharia de produção. Especialista Logística empresarial Graduado em Administração com ênfase em Marketing.
}

RC: 101208

Disponível em: https://www.nucleodoconhecimento.com.br/administracao/o-climaorganizacional 
realizados nas áreas funcionais da clínica, foi identificado que a área mais crítica da organização é a de recursos humanos, assim, chegou-se a problemática dos impactos do clima organizacional sobre os colaboradores, seguindo a pergunta problema: Como a introdução de estratégias voltadas aos recursos humanos pode minimizar o clima organizacional desarmônico existente na organização? A metodologia empregada se baseou em uma pesquisa descritiva, exploratória realizada através do uso de questionários. As ações interventivas foram aplicadas via ferramenta $5 \mathrm{~W} 2 \mathrm{H}$, nas quais objetivaram a implementação da pesquisa de clima organizacional, o estabelecimento da cultura do feedback, a prática da avaliação $360^{\circ}$, planos de treinamento e motivação e a adoção do endomarketing. Espera-se que com essas ações os colaboradores possam desenvolver a relação da gestão com os colaboradores, tornando-os participativos das fases do processo de gestão, a fim de desenvolver suas capacidades e promover o engajamento das equipes, assim, tornando o clima organizacional como diferencial competitivo.

Palavras-chave: Recursos Humanos, Clima organizacional, Ambiente interno, Produtividade.

\section{INTRODUÇÃO}

Este artigo diz respeito ao estudo de caso efetuado na Clínica de Olhos Harley Street, para o qual foram feitas pesquisas, estudos e análises dos resultados obtidos durante o desenvolvimento do diagnóstico organizacional para verificar o resultado que cada área de atuação da organização estava tendo.

Pereira (2018) comenta que estudos e pesquisas são necessários para identificar e resolver problemas. Assim, foi levantada a questão: Como a introdução de estratégias voltadas aos recursos humanos pode minimizar o clima organizacional desarmônico existente na organização? 
Após análise dos dados foi possível identificar a problemática na área de Recursos Humanos, observando a ausência de estratégias voltadas ao clima organizacional que impactava o desenvolvimento e a produção dos colaboradores na organização.

O estudo tem como finalidade a implementação de ferramentas voltadas à área de Recursos Humanos para trabalhar e melhorar a falta da pesquisa de clima organizacional e suas áreas correlatas. As intervenções sugeridas para a implementação que incentivaram e propuseram mudanças positivas compreendem: prática da pesquisa de clima organizacional, feedback, prática da avaliação $360^{\circ}$, implementação de planos de treinamento e motivação e a adoção do endomarketing como meio para desenvolver o público interno.

O presente artigo consiste em uma pesquisa quali-quantitativa, baseada em levantamentos bibliográficos, utilizando para a coleta de dados questionários aplicados durante o desenvolvimento do diagnóstico organizacional.

Diante disto, para promover soluções ao problema identificado na Clínica de Olhos Harley Street a pesquisa foi estabelecida com o objetivo geral de descrever como melhorar o desempenho dos serviços prestados pelos colaboradores por meio da introdução de estratégias para melhoria do clima organizacional. Referente aos objetivos específicos está a realização das ações de pesquisa de clima organizacional, a análise da possibilidade de ações de implementação da cultura de feedbacks e a sugestão da introdução do endomarketing para melhoria do ambiente interno.

\section{FUNDAMENTAÇÃO TEÓRICA}

O referencial teórico foi retirado de uma gama de estudos presente em livros e artigos científicos, com a finalidade de verificar a questão problemática presente neste artigo científico e como as soluções propostas podem agregar a organização em estudo. 
Libório e Terra (2015, p. 15) comentam que "o método científico pode ser definido como um conjunto de regras básicas empregadas em uma investigação científica, com o objetivo de obter resultados, de forma imparcial e confiável."

Prodanov (2013) afirma que diferente de outros conhecimentos como o popular, o científico tem embasamento nos modelos de metodologia e fundamentação que precisam ser seguidos à risca, pois, as informações devem ser classificadas e submetidas a comprovação, para que ofereçam explicações aceitáveis para a pesquisa em estudo.

\subsection{RECURSOS HUMANOS}

$\mathrm{Na}$ organização a função do setor de recursos humanos vai muito além de recrutamento e seleção como outrora já foi no passado, o setor, é o responsável por zelar o bem-estar das pessoas, prezar por um meio ambiente saudável e que valorize o desenvolvimento profissional e pessoal de cada um, além propor e demonstrar que cada colaborador se sinta à vontade para expressar opiniões e sugestões a seus gestores. Também corresponde aos recursos humanos compreender as evoluções das formas de gestão e os interesses, e perspectivas que cada colaborador possa desenvolver.

Cardoso (2021) comenta que o mercado competitivo se tornou cada vez mais exigente, exigindo que as empresas sejam adaptativas e competitivas se quiserem sobreviver. Contudo, neste cenário, a área de recursos humanos tem se mostrado cada vez mais eficiente em auxiliar o alcance das empresas pelos seus objetivos, mantendo-as no mercado através do cuidado com o seu público interno, os colaboradores.

Carvalho (2017) defende que, nas organizações, o papel dos gestores de recursos humanos é fundamental para a compreensão das evoluções que envolvem os projetos de vida de seus colaboradores, a fim de os motivá-los por meio do seu próprio desenvolvimento. O planejamento de recursos humanos tem de ter em conta 
tais perspectivas e trabalhá-las de forma que a comunicação flua da melhor maneira, indo além das recompensas monetárias, proporcionando realização profissional e pessoal.

\subsection{PRÁTICA DA PESQUISA DE CLIMA ORGANIZACIONAL}

O clima organizacional é um dos principais fatores para a organização ter um ambiente harmônico entre a equipe por proporcionar o desenvolvimento e melhorar a relação junto à gestão. Profissionais empenhados se tornam engajados a aderir às metas e objetivos da empresa, assim, tem-se uma abordagem eficaz que ajuda a melhorar o rendimento dos colaboradores, aumentando a satisfação dos clientes.

Begnami (2013) comenta que a motivação de um trabalhador está inteiramente ligada ao Clima organizacional e desta se classifica o grau de frustração ou satisfação dos colaboradores, e como isso influencia o ambiente interno e externo da organização.

Souza (2014) expressa que quanto maior for a intensidade da motivação dos colaboradores alinhado ao quadro pessoal de colaboradores, mais condições e oportunidades as organizações terão. Desta maneira, o clima organizacional é necessário para que os colaboradores da organização possam entender o grau de importância e impacto que desenvolvem dentro de suas organizações, conduzindoos a compreender que os objetivos e as metas da organização também podem corresponder aos seus objetivos individuais de âmbito profissional e pessoal.

\subsection{FEEDBACK}

O termo feedback é de suma importância no comportamento das relações interpessoais em uma empresa. Contudo, indo além de uma comunicação eficaz, as organizações precisam ter um retorno das informações passadas aos colaboradores. No desenvolvimento dessa competência interpessoal o feedback é importante, porque permite que o colaborador se sinta presente e reconhecido, em 
como é visto perante a organização. Essa prática do feedback proporciona retorno quanto aos resultados, podendo ser eles tanto positivos quanto negativos.

Djouki (2017) disserta que a relação profissional entre o gestor e seu colaborador com resultados agradáveis resulta da quantidade de feedback produzido. Se o feedback possuir limitações e for tratado da forma mais rasa possível, não considerando os pontos importantes para um bom desenvolvimento, a relação das partes será ameno, do contrário, quanto a prática do feedback é acentuada e sem limitações, os resultados são frutíferos e os objetivos são alcançados, visto que ambas as partes caminhão em alinhamento.

Vale ressaltar que a inserção do feedback na organização deve ser um processo planejado e preparado junto aos gestores para ser implementado posteriormente, as equipes devem estar cientes dos planos que a organização inserirá para que a adesão ocorra naturalmente, repassando confiabilidade.

Leite et al. (2018) pontuam que no atual cenário organizacional as empresas precisam dar mais zelo ao que pensam e sentem seus colaboradores, e a melhor forma para isto, é criar uma linha de comunicação entre a gestão e o quadro de funcionários, além de ações que propõem o crescimento conjunto. Logo, se tem a existência da ferramenta do feedback que visa aperfeiçoar as formas de relacionamentos, a satisfação dos colaboradores e os seus desempenhos. Desta forma, há também a necessidade de se atentar a preparação das lideranças que serão parte fundamental para a implantação da ferramenta, quanto aos seus níveis de conhecimento a respeito de como o feedback deve ser construtivo e assertivo, preparando-os para saberem receber determinados feedbacks voltados a melhoria dos processos organização.

\subsection{PRATICAR A AVALIAÇÃO 360}

A avaliação $360^{\circ}$, é um modelo gerencial focado em atender o público interno da organização. $\mathrm{O}$ modelo se baseia em realizar análises de desempenho a fim de 
desenvolver as competências indispensáveis para a organização, entendendo onde se encontram os acertos e os erros a serem corrigidos.

Paula (2012) comenta que a avaliação $360^{\circ}$ é um instrumento utilizado pelas organizações para analisar as performances de desempenho que cada área está tendo em relação às metas traçadas e o talento de cada colaborador. A ferramenta também identifica problemas e possíveis deficiências profissionais e quais soluções que podem ser tomadas. Salienta-se que para o sucesso do programa é necessário o comprometimento de todos que fazem parte dos processos e o apoio da gestão.

Badico (2014) expõe que as vantagens que as organizações podem obter com a implementação da avaliação 360을 além de identificar os potenciais de recursos humanos, é adquirir uma intercomunicação aberta na organização, mensurar a diversidade das formas de gestão presente, detectar áreas de investimentos e oportunidades, além de planos de carreiras e desenvolvimento profissional e pessoal.

Perante isto, fica claro que a prática da avaliação $360^{\circ}$ traz inúmeros benefícios à organização e aos colaboradores. Com a implementação será possível identificar os níveis de conhecimentos e quais caminhos possíveis a serem trilhados para melhorias internas.

\subsection{PLANO DE TREINAMENTO E MOTIVAÇÃO}

Motivação é o motor que mantém as engrenagens da organização a pleno fervor, colaboradores motivados agregam competitividade e produtividade às equipes, ambientes onde o coletivo não se sente entusiasmado a desenvolver e entregar o melhor de si, culmina em perdas de resultados e consequentemente enfraquecimento no mercado competitivo. Boas formas de trabalhar o incentivo são através de treinamentos e programas que desenvolvam as habilidades e competências profissionais e pessoais da equipe, ao mesmo passo que desenvolve a própria produção e crescimento como corporação. 
Da Silva (2012) comenta que comumente os treinamentos promovidos pelas organizações se refere às ações sistematicamente pensadas com objetivo de promover melhorias nas áreas de desempenhos atuais e futuras, preparando o sujeito para horizontes inconstantes e imprevisíveis do mercado de trabalho, realizando a ligação das noções da educação e do desenvolvimento.

Assim, torna-se uma abordagem eficaz que ajuda a melhorar o rendimento do funcionário, o que reflete diretamente no nível de serviço e atendimento prestado ao público externo e sua satisfação. Quando uma empresa fornece um treinamento bem planejado e executado em sintonia com a motivação, ela acaba gerando bons resultados. Portanto, é de extrema importância que a gerência esteja em sintonia com seus colaboradores para entender quais ações devem ser tomadas a fim de propor mudanças, tornando-os mais produtivos.

Rosa (2016) ressalta que a motivação dos colaboradores é um fator determinante na organização para sua sobrevivência no mercado competitivo, sendo assim, um desafio diário aos gestores. Pessoas são motivadas segundo o retorno que recebem pelo aquilo que desempenham, sua qualidade, suporte às equipes $e$ relacionamentos. No processo de motivação em um ambiente de trabalho é preciso identificar quais funcionários desempenham melhor aquilo ao que são encarregados, estando a gerência atenta para que estes não passem despercebidos, reduzindo a sua produção em razão do não reconhecimento.

\subsection{APLICAR O ENDOMARKETING}

O endomarketing ou marketing interno são ações focadas no público interno das empresas, ou seja, aos colaboradores, o objetivo da ação é gerar engajamento, incentivo, reconhecimento e estímulo profissional. A relação entre as pessoas da equipe é o foco no endomarketing, então a partir da boa relação entre organização e colaborador, a empresa consequentemente está lapidando sua imagem e fidelizando seus colaboradores com a companhia. 
Oliveira et al. (2016) reforçam que desenvolver a capacitação e satisfação dos funcionários é de extrema importância se as organizações desejam que os seus clientes possam ter a melhor experiência de compra ao adquirir os seus produtos e/ou serviços. Por entre os aspectos perceptíveis no que cerca o endomarketing, o objetivo geral é apresentá-lo para o fomento do crescimento organizacional, utilizando os meios da gestão eficiente do público interno. Analisar as características internas do ambiente, quais os aspectos que o endomarketing pode influenciar para a construção da cultura organizacional e quais fatores implicam para a implementação do endomarketing.

Feitosa et al. (2016) dissertam que o endomarketing é uma ferramenta que age na organização de dentro para fora, onde a prioridade é o colaborador. Dado os resultados que a aplicação do endomarketing desenvolve na organização dando voz ao colaborador, reforçando as relações interpessoais e alinhando os pontos de vistas referente às metas da organização. O diálogo interno entre os gestores e os funcionários precisa ser inspecionado de forma que todos os lados entendam qual mensagem está sendo transmitida e seu objetivo, assim, os objetivos organizacionais devem estar vinculados às metas profissionais a fim de que os colaboradores entendam a sua importância para o sucesso da companhia.

A motivação é o destaque para o comprometimento e o alinhamento em uma organização. Então como podemos ter funcionários motivados para o trabalho? Para que uma organização tenha funcionários motivados para o trabalho, esta precisa vender sua visão de negócio, ou seja, o compromisso por parte dos funcionários só acontece quando há o compartilhamento da visão de que o crescimento da empresa é o seu próprio crescimento, e o instrumento para que isso aconteça é o Endomarketing. O funcionário deve ser visto como o primeiro cliente de qualquer empresa, pois, se o cliente interno está feliz consequentemente estará apto a satisfazer os clientes externos, assim, o crescimento de ambos, organização e colaborador, se desenvolverão lado a lado. 


\section{MATERIAIS E MÉTODOS}

A metodologia compreende os instrumentos que os pesquisadores utilizam para obter elementos e identificar problemas. Menezes et al. (2019) comentam que diversificados são os modelos de pesquisa e como são relacionados. Dado essas diferenças, cabe ao pesquisador definir qual será o seu propósito de estudo considerando o que a pesquisa deseja alcançar.

As metodologias variam conforme as pesquisas que cada área estudada demanda.

\subsection{PROCEDIMENTOS METODOLÓGICOS}

Procedimentos são processos e metodologias empregadas durante a pesquisa, os dados coletados são agrupados para identificar e solucionar a problemática. Neste estudo, foram realizadas pesquisas descritivas, exploratória através de questionários aplicados aos funcionários e a gestão. Quanto ao método, foi aplicado o hipotéticodedutivo, baseado em um estudo de caso realizado através de levantamentos e pesquisas bibliográficas.

\subsection{QUANTO À NATUREZA}

Como comenta Zanella (2013), os métodos quantitativo e qualitativo geralmente são mais utilizados nas pesquisas voltadas para administração. O quantitativo utiliza métodos derivados de ciências físicas, estatística e matemática, caracterizando-se pela adoção de métodos conclusivos e na busca de objetividade, validade e confiabilidade. Enquanto o qualitativo tem como origem a antropologia e utiliza métodos incisivos, tensionando a descoberta, a identificação e as descrições mais aprofundadas.

A natureza de abordagem utilizada foi a metodologia da pesquisa qualitativa, baseada em pesquisas exploratórias via questionários na organização. Mediante a isto, pode ser possível implementar também a natureza aplicativa, visto que o projeto se mostrou viável para implementação.

RC: 101208

Disponível em: https://www.nucleodoconhecimento.com.br/administracao/o-climaorganizacional 


\subsection{QUANTO AOS FINS}

De acordo com Nunes et al. (2016), a pesquisa descritiva contém o estudo observacional, em que se confronta duas equipes similares, assim, o processo visa identificar, registrar e analisar as características, fatos ou variáveis que se associam com o fenômeno ou processo. A grande colaboração da pesquisa descritiva é possibilitar novas perspectivas de uma realidade já conhecida.

Em relação aos fins, a pesquisa pode ser explicativa, exploratória, descritiva intervencionista ou aplicada, sendo, neste estudo, utilizadas as pesquisas de natureza descritiva em materiais de estudos bibliográficos, apresentando também traços exploratórios, onde se fez pesquisas via questionários aos colaboradores e aos gestores da organização.

\subsection{QUANTO AOS MEIOS}

Aragão (2017) comenta que o estudo de caso permite, mediante 0 isolamento de pequenos grupos ou casos, entender determinados fatores e consequências. Partindo do princípio de que todo caso que se pesquise em profundidade pode ser classificado como representativo a muitos outros, ou em alguns casos, até semelhante podendo ou não ter a mesma aplicação.

Quanto aos meios, foi utilizado o estudo de caso em que se buscou entender fenômenos e dados pertinentes às complicações identificadas, os fatores que corroboram para a ocorrência dos fenômenos, suas causas e impactos. E quais as medidas que podem ser tomadas para a empresa em estudo.

\subsection{CARACTERÍSTICAS DA EMPRESA}

A Clínica de Olhos Harley Street, localizada na Avenida Eduardo Ribeiro, № 654, sala 208, centro, CEP 69010-001, é uma das pioneiras no ramo da oftalmologia em Manaus, inaugurada no dia 19 de maio de 1987. Sendo assim, esta vem atuando a mais de 34 anos na prestação de serviços em saúde ocular e tornou-se referência 
na região norte do país. Para melhorar o atendimento foi feita uma filial na Rua Monsenhor Coutinho, n 871, Bairro Centro, CEP 69010-110, otimizando o fluxo de pessoas em um espaço maior, assim separando centro cirúrgico e atendimento ambulatorial. Posto isso, vale ressaltar que a clínica continua a expandir seu espaço físico tanto quanto suas tecnologias para proporcionar sempre o melhor atendimento.

\section{RESULTADOS E DISCUSSÕES}

Verificou-se com os estudos e as pesquisas efetuadas durante o período do diagnóstico organizacional as médias de desempenho de cada setor da organização. As informações obtidas foram reunidas para serem comparadas entre si. Desta forma, assim como toda organização que possui pontos forte e fracos, a empresa demonstrou ter resultados bem semelhantes entre as suas áreas, como pode-se observar no gráfico 1:

Gráfico 1: Medição de Desempenho

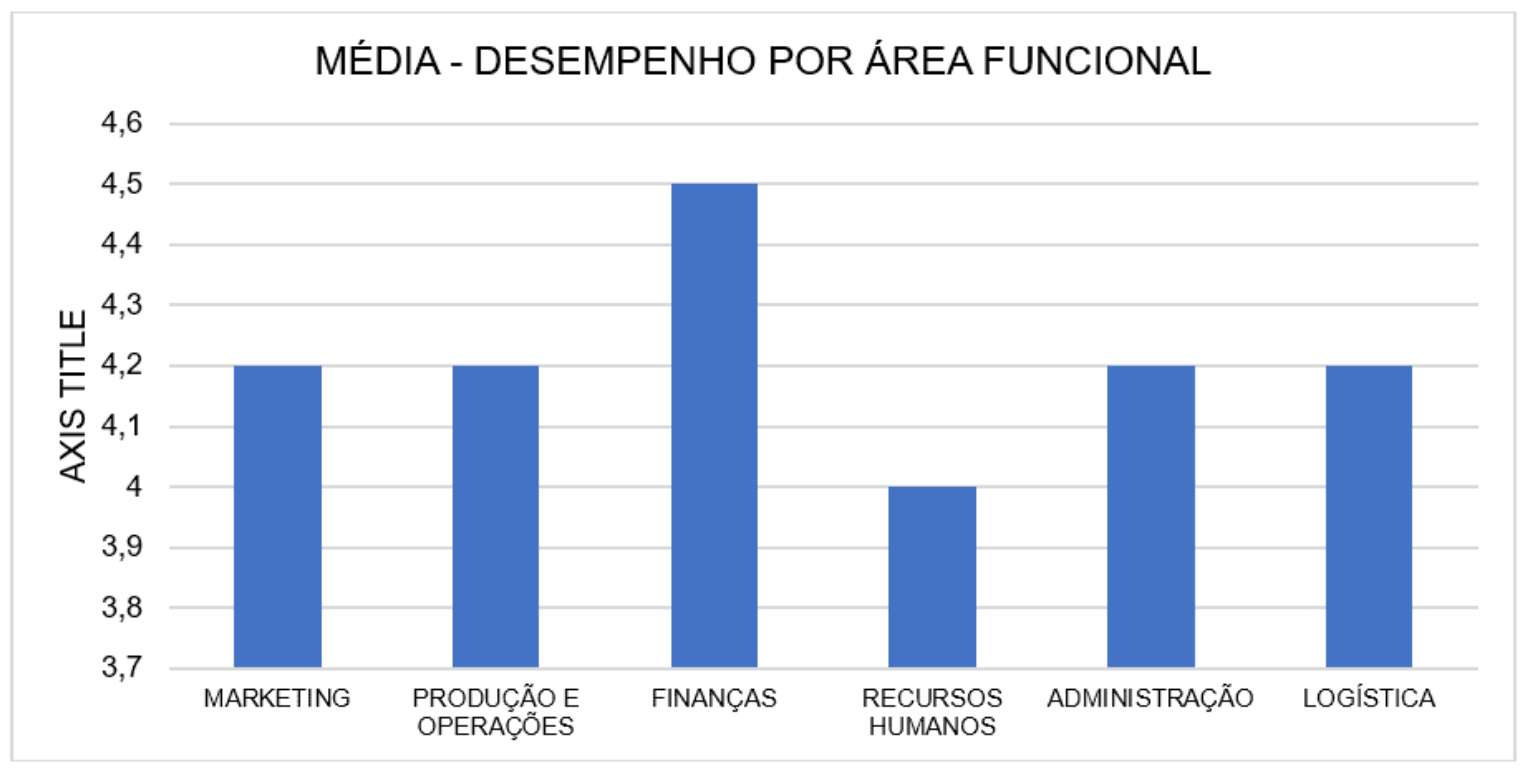

Fonte: Elaborado pelos autores com base na coleta de dados, 2021. 
Averiguou-se na análise a média dos resultados que cada setor da3 empresa Clínica de Olhos Harley Street obteve. Finanças obteve um desempenho que o põe em destaque quando comparado aos demais setores, em sequência, quatro áreas obtiveram a mesma performance, Marketing, Operações, Administração e Logística, assim, o pior rendimento foi constatado na área de Recursos Humanos.

Posto isso, destaca-se que a condução da pesquisa foi realizada com cautela e atenção, para que todas as variáveis fossem consideradas e posteriormente esclarecidas via questionário junto a equipe. Como pode-se observar no quadro 1.

Quadro 1 - Grau de Avaliação de Recursos Humanos

\begin{tabular}{|l|l|l|l|l|l|l|l|}
\hline ÁREA FUNCIONAL & \multicolumn{3}{|l|}{ NÍVEL OU GRAU DE AVALIAÇÃO } \\
\hline RECURSOS HUMANOS & $\begin{array}{l}\text { Ponto } \\
\text { muito }\end{array}$ & $\begin{array}{l}\text { Ponto } \\
\text { forte }\end{array}$ & $\begin{array}{l}\text { Ponto } \\
\text { médio }\end{array}$ & $\begin{array}{l}\text { Ponto } \\
\text { fraco }\end{array}$ & $\begin{array}{l}\text { Ponto } \\
\text { muito } \\
\text { fraco }\end{array}$ \\
\hline $\mathbf{1}$ & $\begin{array}{l}\text { Estima-se o índice de absenteísmo } \\
\text { por funcionário }\end{array}$ & $\mathbf{5}$ & $\mathbf{3}$ & $\mathbf{2}$ & & \\
\hline $\mathbf{2}$ & $\begin{array}{l}\text { Avalia-se o nível de aprendizagem } \\
\text { após admissão }\end{array}$ & & & & \\
\hline $\mathbf{3}$ & $\begin{array}{l}\text { Apresenta-se um baixo índice de } \\
\text { rotatividade na empresa (turnover) }\end{array}$ & $x$ & & & \\
\hline $\mathbf{4}$ & $\begin{array}{l}\text { Averígua-se o nível de produtividade } \\
\text { por colaborador }\end{array}$ & $x$ & & & \\
\hline $\mathbf{5}$ & $\begin{array}{l}\text { Realiza-se pesquisas sobre clima } \\
\text { organizacional }\end{array}$ & & & & \\
\hline $\mathbf{6}$ & $\begin{array}{l}\text { Analisa-se por mês o custo médio } \\
\text { por empregado }\end{array}$ & $x$ & & & \\
\hline $\mathbf{7}$ & $\begin{array}{l}\text { Observa-se motivação em relação } \\
\text { aos benefícios e recompensas }\end{array}$ & & & & \\
\hline
\end{tabular}




\begin{tabular}{|c|c|c|c|c|c|c|}
\hline \multirow[b]{2}{*}{8} & oferecidos pela empresa & & & \multirow[b]{2}{*}{$\mathrm{x}$} & & \\
\hline & $\begin{array}{l}\text { Enfatiza-se o processo de } \\
\text { recrutamento e seleção na empresa }\end{array}$ & & & & & \\
\hline 9 & $\begin{array}{l}\text { Observa- se preocupação com bem- } \\
\text { estar e saúde do colaborador }\end{array}$ & $\mathrm{x}$ & & & & \\
\hline 10 & $\begin{array}{l}\text { Trabalha-se a rotatividade de } \\
\text { funções }\end{array}$ & $x$ & & & & \\
\hline & $\operatorname{TAL}(\Sigma)$ & 25 & 8 & 6 & 0 & 1 \\
\hline & DIA POR GRAU (POR COLUNA) & 2,5 & 0,8 & 0,6 & 0 & 0,1 \\
\hline & SEMPENHO DA ÁREA & 4 & & & & \\
\hline
\end{tabular}

Fonte: Elaborado pelos autores com base em dados coletados, 2021

Aponta-se que os fatores críticos apresentados no Quadro 1 ligam o alerta para uma das bases inerentes a um bom desenvolvimento na relação entre a organização e os seus empregados, ou seja, a quase inexistência do clima organizacional na organização, assim, passou a se buscar entender como a introdução de estratégias voltadas aos recursos humanos pode minimizar o clima organizacional desarmônico existente na organização?

\subsection{PLANEJAMENTO DE AÇÕES}

O planejamento de ações interventivas consiste em práticas que visam melhorar os déficits de determinados setores, sobre quando serão aplicadas e como serão, para alcançar os objetivos desejáveis. 
Quadro 2 - Proposta de ações interventivas para do desempenho de Recursos Humanos

\begin{tabular}{|c|c|c|c|c|}
\hline \multicolumn{5}{|c|}{ QUADRO DE AÇÕES INTERVENTIVAS } \\
\hline ITEM & AÇÕES INTERVENTIVAS & CRONOLOGIA & DURAÇÃO & CUSTO R\$ \\
\hline 1 & Implementação da pesquisa de clima organizacional & set/21 & 5 dias & $\mathrm{R} \$ 900,00$ \\
\hline 2 & Estabelecer o repasse do feedback & set/21 & 3 dias & 600,00 \\
\hline 3 & Praticar a avaliação 360 & set/21 & 10 dias & $\mathrm{R} \$ 1.000,00$ \\
\hline 4 & Implementação do plano de treinamento e motivação & out/21 & 4 dias & $R \$ 1.500,00$ \\
\hline 5 & Aplicar o Endomarketing & out/21 & 10 dias & $\mathrm{R} \$ 1.000,00$ \\
\hline \multicolumn{4}{|c|}{ TOTAL } & $R \$ 5.000,00$ \\
\hline
\end{tabular}

Fonte: Elaborado pelos autores com base em dados coletados, 2021.

Trata-se de ações pensadas conforme a problemática encontrada no Diagnóstico Organizacional sobre como a introdução de estratégias podem minimizar o clima organizacional e como isto afeta o desenvolvimento pessoal dos colaboradores. A proposta foi elaborada por meio da ferramenta $5 \mathrm{w} 2 \mathrm{~h}$, que propõe às empresas maneiras de registrar, organizar e planejar ações baseadas nas questões: por quem, onde, quando, como, por que, e quais serão os custos.

\subsubsection{IMPLEMENTAÇÃO DA PESQUISA DE CLIMA ORGANIZACIONAL}

Entende-se que o clima organizacional é um dos principais fatores para se ter um ambiente profissional saudável, empenhado e engajado para se manter alinhado com as metas e os objetivos da organização.

Notou-se durante o diagnóstico que o clima não era um tema tratado entre a gerência e os colaboradores, onde havia apenas a demanda de um lado, enquanto o outro não se sentia confortável a ponto de expor pensamentos ou ideias. Logo, partindo deste ponto se faz necessário o início do processo da implementação da pesquisa de clima organizacional, em que, na falta de um profissional capacitado na própria instituição, optou-se por admitir uma empresa especializada em consultoria da gestão de pessoas via contrato com tempo limitado. 
Quadro 3 - Implementação de Pesquisa de Clima Organizacional

\begin{tabular}{|c|l|}
\hline \multicolumn{2}{|c|}{ Implementação de Pesquisa de Clima Organizacional } \\
\hline O que? & Pesquisa de Clima Organizacional \\
\hline Por quê? & $\begin{array}{l}\text { Para avaliar como está o entendimento dos colaboradores sobre a importância das } \\
\text { atividades que exercem e se há comunicação com a Gerência }\end{array}$ \\
\hline Onde? & Clínica de Olhos Harley Street \\
\hline Quando? & $1^{\circ}$ semana de Setembro/2021 \\
\hline Quem? & Empresa de Consultoria Terceirizada \\
\hline Como? & $\begin{array}{l}\text { Via empresa de consultoria, por implementação de formulários online(Google Forms), sem } \\
\text { indentificação afim de manter o anonimato e integridade do colaborador }\end{array}$ \\
\hline Quanto? & $\mathrm{R} \$ 900,00$ \\
\hline
\end{tabular}

Fonte: Elaborado pelos autores com base em dados coletados, 2021.

Conforme o quadro acima, reconheceu-se a necessidade de implementar um plano de ação para tratar o clima organizacional, espera-se com os resultados nivelar o entendimento dos colaboradores sobre a importância das atividades que exercem e sobre como está o engajamento da equipe. O método foi executado na Harley Street na primeira semana de setembro de 2021 via empresa de consultoria terceirizada, foram usados formulários online sem identificação de modo a manter o anonimato e integridade dos colaboradores e o valor do investimento foi de $\mathrm{R} \$ 900,00$. Assim, tendo em vista que novos processos tecnológicos podem causar receio em alguns, averiguou-se também sobre a importância de tratar os feedbacks.

\subsubsection{ESTABELECER O REPASSE DO FEEDBACK}

Destaca-se o feedback como uma importante ferramenta para entender como está o nível de satisfação das pessoas que fazem parte da organização, a comunicação aberta junto aos gestores possibilita um melhor desempenho nas atividades realizadas. O Feedback não se limita a apontar acertos e erros, deve ser entendido como um grande beneficiador aos modelos de gestão para melhoria contínua da qualidade de produção e desenvolvimento. 
Quadro 4 - Estabelecer o Repasse do Feedback

\begin{tabular}{|l|l|}
\hline \multicolumn{2}{|c|}{ Estabelecer o Repasse do Feedback } \\
\hline O que? & Avaliar todos os funcionários \\
\hline Por quê? & $\begin{array}{l}\text { Fazer com que a empresa adquira a cultura do feedback de forma aberta e } \\
\text { acessível a todos }\end{array}$ \\
\hline Onde? & Clínica de Olhos Harley Street \\
\hline Quando? & $2^{\circ}$ semana de Setembro/2021 \\
\hline Quem? & Empresa de Consultoria Terceirizada \\
\hline Como? & Aplicação de Questionários como pesquisa \\
\hline Quanto? & R\$ 600,00 \\
\hline
\end{tabular}

Fonte: Elaborado pelos autores com base em dados coletados, 2021.

Propôs-se avaliar todos os funcionários que se mostraram dispostos a participar sem o caráter da obrigação, sendo feito de forma espontânea através de questionários aplicados aos participantes. O questionário foi aplicado na Clínica na segunda semana de setembro de 2021, tendo como responsável a empresa de consultoria terceirizada, o valor do investimento para a realização foi de $R \$ 600,00$ para os dias que os questionários foram aplicados.

Concluiu-se como resultado da ação que a organização precisa adotar uma cultura que pratique o feedback livre e acessível a todos, onde os colaboradores se sintam confortáveis o suficiente para expor pensamentos e ideias aos seus gestores.

\subsubsection{PRATICAR A AVALIAÇÃO 360}

Adotou-se também a implementação da ferramenta de Avaliação $360^{\circ}$, atuando como uma auxiliar no diagnóstico dos processos que ocorrem na organização, verificando formas e meios de fortalecer as aptidões dos colaboradores, como estão sendo conduzidos, o que está sendo feito e o que está sendo deixado de ser feito, quais correções deverão ser realizadas e o que precisará ser revisto e reformulado. A avaliação é um processo que em comparação aos demais demandará mais tempo para sua execução e resultados, porém, sua aplicação é indispensável para que as mudanças se tornem perceptíveis e para que uma nova cultura possa ser criada. 
Quadro 5 - Implementação da Avaliação $360^{\circ}$

\begin{tabular}{|l|l|}
\hline \multicolumn{2}{|c|}{ Implementação da Avaliação 360} \\
\hline O que? & Avaliação 360 \\
\hline Por quê? & $\begin{array}{l}\text { Com objetivo de melhorar a qualidade dos processo e auxiliar o funcionário a } \\
\text { entender os impactos e importância daquilo que desenvolve }\end{array}$ \\
\hline Onde? & Clínica de Olhos Harley Street \\
\hline Quando? & $3^{\circ}$ e $4^{\circ}$ semana de Setembro/2021 \\
\hline Quem? & Empresa de Consultoria Terceirizada \\
\hline Como? & Empregando a avaliação 360 \\
\hline Quanto? & R\$ $1.000,00$ \\
\hline
\end{tabular}

Fonte: Elaborado pelos autores com base em dados coletados, 2021.

Compreende-se a necessidade da implementação da Avaliação $360^{\circ}$ com o objetivo de melhorar a qualidade dos processos e auxiliar os funcionários a atenderem a demanda, entendendo os impactos daquilo que desenvolvem. A implementação ocorreu na Clínica de Olhos Harley Street na terceira e quarta semana de setembro de 2021. O projeto teve como responsável uma empresa terceirizada de consultoria e o valor para custear o projeto foi de $\mathrm{R} \$ 1.000,00$.

Acredita-se que com a avaliação $360^{\circ}$ os processos fluam de forma mais clara, sem ruídos ou gargalos com comunicação limpa e objetiva, e que estes pontos impactem de forma direta e positiva os desempenhos da equipe.

\subsubsection{IMPLEMENTAÇÃo DE PLANO DE TREINAMENTO E MOTIVAÇÃO}

Pontuou-se a importância do desenvolvimento e capacitação profissional dos colaboradores e os bons resultados que podem ser obtidos, contudo, deve ser conduzido de forma cautelosa para entender qual a necessidade que deve ser suprida, onde está a carência e qual a melhor forma de propiciar o aprimoramento profissional. 
Quadro 6 - Implementação de Plano de Treinamento e Motivação

\begin{tabular}{|l|l|}
\hline \multicolumn{2}{|c|}{ Implementação de Plano de Treinamento e Motivação } \\
\hline O que? & Plano de Treinamento e Motivação \\
\hline Por quê? & $\begin{array}{l}\text { Com intuido de desenvolver as habilidades de cada funcionário, além de incentivar } \\
\text { o crescimento profissional de cada um. }\end{array}$ \\
\hline Onde? & Clínica Harley Street \\
\hline Quando? & $1^{\circ}$ semana de Outubro/2021 \\
\hline Quem? & Empresa de Consultoria Terceirizada \\
\hline Como? & $\begin{array}{l}\text { Ações e Planejamento de programas que visem a capacitação e aprimoramento das } \\
\text { habilidades além das exercidas, onde se prepara o profissional para novas } \\
\text { oportunidades }\end{array}$ \\
\hline Quanto? & R\$ $1.500,00$ \\
\hline
\end{tabular}

Fonte: Elaborado pelos autores com base em dados coletados, 2021.

Constatou-se durante o diagnóstico que, na média, os funcionários da Clínica Harley Street chegaram a iniciar alguma graduação, assim indicando o interesse no crescimento profissional, porém, evidencia-se que na própria organização não havia planos de treinamentos para a qualificação e disseminação de competências internas. Portanto, foi contratada uma empresa terceirizada para fazer uma pesquisa com os funcionários, medindo seu nível profissional e aplicando, a partir da primeira semana de outubro, um programa baseado em metas futuras, focando em desenvolver as habilidades dos profissionais e promover seu engajamento no trabalho. Este projeto foi o que mais demandou o investimento de capital para aplicação, no valor de $\mathrm{R} \$ 1.500,00$.

Espera-se como resultado colaboradores motivados, competentes e um maior leque de habilidades em outras funções à medida que a empresa estimula seu potencial de crescimento com novas oportunidades.

\subsubsection{APLICAR O ENDOMARKETING}

Marketing interno ou Endomarketing está relacionado ao público interno da organização, ou seja, observou-se que planejamentos e ações voltadas ao ambiente interno da empresa tem o objetivo de criar um vínculo empresa-funcionário, de modo que o segundo se sinta parte da organização, motivado a se desenvolver e a se

RC: 101208

Disponível em: https://www.nucleodoconhecimento.com.br/administracao/o-climaorganizacional 
expressar ou propor melhorias para os processos da sua área ou que estejam correlacionados.

Quadro 7 - Implementação da Ferramenta de Endomarketing

\begin{tabular}{|l|l|}
\hline \multicolumn{2}{|c|}{ Implementação da ferramenta de Endomarketing } \\
\hline O que? & Endomarketing \\
\hline Por quê? & $\begin{array}{l}\text { Com o objetivo de melhorar o ambiente interno da empresa, a integração entre os } \\
\text { funcionários e o engajamento de cada um. }\end{array}$ \\
\hline Onde? & Clínica de Olhos Halrey Street \\
\hline Quando? & $2^{\circ}$ e $3^{\circ}$ semana de Outubro/2021 \\
\hline Quem? & Empresa de Consultoria Terceirizada \\
\hline Como? & $\begin{array}{l}\text { Via empresa de consultoria, por implementação de formularios que possibilitem a } \\
\text { sugestão de ações por parte dos colaboradores }\end{array}$ \\
\hline Quanto? & R\$ $1.000,00$ \\
\hline
\end{tabular}

Fonte: Elaborado pelos autores com base em dados coletados, 2021.

Contratou-se uma empresa de consultoria terceirizada para implementar o uso do endomarketing no ambiente interno por meios de engajamento nos processos organizacionais, promovendo a interação do funcionário com a empresa em eventos, treinamentos, valorizações e atividades de reconhecimento profissional. O Projeto ocorreu na segunda e terceira semana de outubro usando como método a inovação no canal de comunicação interna e o investimento aplicado foi de $R \$ 1.000,00$. Portanto, concluiu-se que o endomarketing começa pelo reconhecimento do colaborador e daquilo que o motiva e o mantém engajado para alcançar metas em conjunto a organização.

Reflete-se como objetivo melhorar a integração dos funcionários na organização, dando-lhes o reconhecimento pelo aquilo que desempenham, e que os crescimentos de ambos estejam alinhados em uma mesma direção, criando um vínculo de parceria e comprometimento na busca pelo crescimento.

\section{CONSIDERAÇÕES FINAIS}

Partindo dos resultados do estudo de caso realizado na clínica de Olhos Harley Street foi possível observar a importância e influência do clima organizacional na

RC: 101208

Disponível em: https://www.nucleodoconhecimento.com.br/administracao/o-climaorganizacional 
organização. As ações sugeridas buscam implementar estratégias que desenvolvam a pesquisa de clima organizacional na Clínica de Olhos Harley Street, tratando principalmente da relação entre o colaborador e a gestão.

Vale ressaltar que se trata de um estudo realizado em uma determinada organização, assim, a possibilidade de resultados e mudanças variam segundo a corporação, podendo novos estudos agregar novas experiências e resultados.

Através dos resultados obtidos no Diagnóstico Organizacional aplicado na Clínica de Olhos Harley Street, foi possível detectar um déficit de desempenho na área de recursos humanos com relação aos resultados apresentados pelas demais áreas funcionais da clínica.

A pergunta norteadora do estudo foi: Como a introdução de estratégias voltadas aos recursos humanos pode minimizar o clima organizacional desarmônico existente na organização? Em relação ao problema identificado, obteve-se êxito no sentido de preparar um conjunto de ações interventivas que orientam os gestores da organização de forma clara e coesa a melhoria do clima organizacional na clínica. As abordagens utilizadas se deram por meio de pesquisas internas para entender qual o nível do clima organizacional na clínica, de feedbacks para compreender e dar voz às equipes e do endomarketing para acompanhar o público interno a fim de entender aquilo que pode ser melhorado. Tais estimativas podem proporcionar a melhoria do clima organizacional, da performance e dos resultados que podem ser obtidos.

Portanto, apoiando-se na metodologia de pesquisa exploratória embasada em estudos realizados, conclui-se que desenvolver o clima organizacional é um aspecto primordial para empresas que desejam equipes motivadas e com senso de comprometimento com aquilo que realizam.

O presente trabalho proporcionou os resultados esperados na empresa estudada no sentido de elaborar uma proposta interventiva que solucionou os problemas 
identificados no diagnóstico, deixando um legado teórico fundamentado para futuras pesquisas acadêmicas.

\section{REFERÊNCIAS}

ARAGÃO, J. W. M. de; MENDES NETA, M. A. H. Metodologia científica. Superintendência de Educação a Distância, 2017.

BADICO, G. B. Avaliação de Desempenho na Empresa Politriz: Um Estudo De Caso. Universidade Federal de Uberlândia, 2014.

BEGNAMI, M. L. V.; ZORZO, A. Clima Organizacional: Percepção Es E Aplicabilidade. Revista Científica da FHO| UNIARARAS, v. 1, n. 2, 2013.

CARDOSO, L. Práticas de Gestão de Recursos Humanos e Desempenho Organizacional. Instituto Universitário de Ciências Psicológicas, Sociais e da Vida, 2012.

CARVAlHO, A.; RUA, O. L. Gestão de Recursos Humanos: Abordagem Das Boas Práticas. Vida Econômica Editorial, 2017.

DA SILVA, H. F. D. et al. A Aprendizagem, Treinamento e Desenvolvimento nas Organizações. 2012.

DJOUKI, D. O Feedback como Ferramenta de Gestão de Pessoas nas Empresas. Revista De Pós-Graduação Multidisciplinar, [S.I.], v. 1, n. 1, p. 45-56, junho de 2017.

FEITOSA, Á. M. de V. et al. O Endomarketing como Estratégia de Gestão e Crescimento Organizacional. Race-Revista De Administração Do Cesmac, v. 1, n. $1,2016$.

LEITE, A. S. et al. O Feedback nas Organizações: Técnicas e Estratégias para Fornecer um Feedback. Revista de Humanidades, Tecnologia e Cultura, 2018. 
LIBÓRIO, D.; TERRA, L. Metodologia Científica. Editora Laureate International Universities, 2015.

MENEZES, A. H. N. et al. Metodologia Científica: Teoria e Aplicação na Educação a Distância. Universidade Federal do Vale do São Francisco, PetrolinaPE, 2019.

NUNES, G. C. Pesquisa Científica: Conceitos Básicos. Revista De Psicologia, v. 10, n. 29, p. 144-151, 2016.

OLIVEIRA, A. A. et al. O Endomarketing como Estratégia na Gestão de Pessoas: Influências de Clima e Cultura nas Organizações. Revista de Economia, Empresas e Empreendedores CPLP, v. 2, n. 1, p. 24-41, 2016.

PAULA, M. A. de. Aplicação da Gestão por Competência e Avaliação $360^{\circ}$ como Instrumento de Avaliação. Porto Alegre, 2012.

PEREIRA, A. S. et al. Metodologia da Pesquisa Científica. 1a Edição. Universidade Federal de Santa Maria, UFSM, 2018.

PRODANOV, C. C.; DE FREITAS, E. C. Metodologia do Trabalho Científico: Métodos e Técnicas da Pesquisa e do Trabalho Acadêmico. 2ª Edição. Editora Feevale, 2013.

ROSA, R. H. R. A Importância da Liderança e Motivação nas Organizações. In: XII Congresso Nacional de Excelência em Gestão. 2016.

SOUSA, J. P. B. de. Clima Organizacional: A influência da Motivação na Gestão Pública. Universidade da Integração Internacional da Lusofonia Afro-Brasileira, Redenção: Ceará, 2014.

ZANELLA, L. C. H. Metodologia de Pesquisa. 2a Edição. Florianópolis: Departamento de Ciências da Administração/UFSC, 2013. 
Enviado: Outubro, 2021.

Aprovado: Novembro, 2021. 